Volume 13, n, 2, ano, 2017

\title{
O PLANO MUNICIPAL DE EDUCAÇÃO E A "IDEOLOGIA DE GÊNERO": \\ Cenas e discursos da mídia e a discriminação de jovens lgbtt nas escolas
}

RESUMO: Este artigo teve como objetivo analisar as cenas e discursos da mídia durante a discussão do Plano Municipal de Educação (PME) em Sorocaba-SPe elaborar algumas considerações sobre o quanto estes resultados ressoam os dados sobre discriminação de jovens LGBTT nas escolas. Foi realizada, portanto, a coleta de um total de 52 reportagens, artigos de jornais, imagens na internet em 2015 e, em seguida, estes documentos foram sistematizados a fim de evidenciar os seus principais argumentos, ideias e práticas. Os resultados indicam que ações, respaldadas por um PME sem as questões de gênero e da diversidade sexual em seu texto, podem ameaçar os direitos sexuais e reprodutivos de jovens nas escolas, contribuindo, deste modo, para o agravamento da violência contra pessoas LGBTT. Além disso, estes discursos dão sentido e se traduzem em práticas sociais, de poder, de regulação e controle de corpos, e, neste caso, de corpos de jovens das escolas brasileiras; e, mais ainda, revelam uma relação de complementariedade e interdependência entre religiões cristãs e poderes legislativos e executivos, o que coloca perigosamente em questão a laicidade do Estado brasileiro.

\section{Palavras-chave: Plano Municipal de Educação. Juventude LGBTT. Educação}

\section{THE MUNICIPAL EDUCATION PLAN AND "GENDER IDEOLOGY":}

\section{Scenes and media discourses and the discrimination of Young lgbtt people in schools}

\begin{abstract}
This article intend to analyze the scenes and media discourses during the discussion of the Municipal Plan of Education (PME) in Sorocaba-SP and elaborate some considerations on how much these results resonate the data on discrimination of LGBTT young people in schools. A total of 52 articles, newspaper articles and images were collected from Internet in 2015, and these documents were systematized to highlight their main arguments, ideas and practices. The results indicated that actions, based on PME without gender and sexual diversity issues in its text, can threaten the sexual and reproductive rights of young people in schools, thus contributing to the aggravation of violence against LGBTT people. In addition, these discourses give meaning and are translated into social, power, regulation and control practices over the bodies, and in this case, over the bodies of young people from Brazilian schools; and, moreover, reveal a relationship of complementarity and interdependence between

\footnotetext{
${ }^{1}$ Professora Associada da Universidade Federal de São Carlos (UFSCar). Departamento de Ciências Humanas e Educação, campus Sorocaba. Doutorado em Educação pela Universidade Estadual de Campinas (UNICAMP), Mestrado em Psicologia pela Pontifícia Universidade Católica (PUCCAMP) de Campinas e Graduação em Psicologia pela Universidade Federal de Pernambuco (UFPE). Centro de Ciências Humanas e Biológicas da Universidade Federal de São Carlos (UFSCar), Campus Sorocaba viviane@ufscar.br
} 
REVISTAELETRÔNICA

DA GRADUAÇÃO/PÓS-GRADUAÇÃO EM EDUCAÇÃ O

ISSN. 1807-9342

Volume 13, n, 2, ano, 2017

Christian Religions and legislative and executive powers, which puts in danger the secularism of the Brazilian State

Key-words: Municipal Plan of Education. LGBTT Youth. Education

\section{INTRODUÇÃO}

Segundo reportagem de 23 de janeiro de 2017, publicada no portal do G1 de Arquimedes e Vale do Jamari ${ }^{2}$, e exaustivamente compartilhada nas redes sociais, o prefeito e vereadores de Arquimedes (RO) decidiram proibir que as escolas municipais entregassem quaisquer livros que contivessem o tema gênero e orientação sexual aos estudantes. Assim, o poder executivo exigiu que todas as páginas de livros didáticos que falem ou mostrem a diversidade sexual fossem arrancadas antes de serem entregues aos estudantes.

Na mesma reportagem um vereador afirmou que $90 \%$ da população da cidade éa favor da medida e que existe uma lei municipal, em vigência,que não permite conteúdos com “ideologia de gênero"no ensino fundamental, já que estes conteúdos também foram retirados do Plano Municipal e Nacional de Educação.

Não é de se surpreender que a sessão de comentários desta notícia tenha sido majoritariamente preenchida com falas de pessoas que parabenizaram a decisão dos vereadores e prefeito da cidadee que quase a totalidade destes comentários foielaborada com argumentos religiosos e frases agressivas contra homossexuais.

Esta notícia instiga algumas questões importantes: diante de um contexto de aumento da visibilidade das pessoas LGBTT $^{3}$ do Brasil e, por outro lado, um aumento de discursos de ódio direcionado a estas pessoas por políticos e religiosos, na mídia e nas redes sociais, como educadores/as podem tratar do tema de gênero e da diversidade sexual com estudantes jovens, quando leis e decisões do poder legislativo e executivo, pautadas muitas vezes por noções religiosas, tem proibido o debate destes temas na escola? Que impacto pode ter estas proibições no aumento da discriminação de jovens LGBTT no Brasil? Quais as estratégias políticas possíveis encontradas por educadores/as e pelos próprios/as jovenspara a superação da discriminação LGBTTfóbica neste contexto?É necessário ressaltar que o Brasil é considerado um dos países que mais comete assassinatos de pessoas lésbicas, gays, bissexuais e transexuais e travestis (LGBT) no mundo.

\footnotetext{
${ }^{2}$ http://g1.globo.com/ro/ariquemes-e-vale-do-jamari/noticia/2017/01/prefeitura-manda-arrancar-paginas-delivros-escolares-sobre-homossexuais.html, Acesso em: 26 de janeiro de 2017.

${ }^{3}$ Lésbicas, Gays, Bissexuais e Transexuais, Travesti e Transgênero.
} 
REVISTAELETRÔNICA

DA GRADUAÇÃO/PÓS-GRADUAÇÃO EM EDUCAÇÃ O

ISSN. 1807-9342

\section{Volume 13, n, 2, ano, 2017}

Em levantamento feito com base em notícias que circulam na internet ou publicadas em jornais, o último relatório do Grupo Gay da Bahia apontou para o ano de 2016como o mais violento contra pessoas LGBTT desde 1970. Segundo a entidade, 343 pessoas foram mortas em todo o Brasil por razão de orientação sexual e identidade de gênero: 173 eram gays, 144 trans (travestis e transexuais), 10 lésbicas, 4 bissexuais e 12 heterossexuais (parentes ou conhecidos de LGBTs que foram assassinados por algum envolvimento com eles). O Estado de São Paulo aparece com o maior número de assassinatos do total apresentado, 49, seguido da Bahia, com 32 mortes, Rio de Janeiro e Amazonas, com 30 e 28 mortes respectivamente (GRUPO GAY DA BAHIA, 2017)

Ainda segundo o Relatório do GGB 2017, predominaram as mortes de pessoas LGBTT com idades entre 19 e 30 anos (32\%) e de menores de 18 anos, que representam 20,6\% das vítimas. Estes resultados apresentados reforçam a vulnerabilidade da população jovem LGBTTà crimes e violências homo, lesbo, bi e transfóbica.

Não se sabe quantos desses casos tiveram a homofobia como motivação principal.Como ela não é crime no Brasil, torna-semais difícil estatísticas governamentais sobre estes casos.Embora a metodologia utilizada nos relatórios do GGB e outros levantamentos sobre assassinados de pessoas LGBTTtenham limitações em razão desta falta de tipificação do crime de homofobia, o que leva a dificuldades para acessar os dados oficiais, ainda assim, estes levantamentos apontam para e corroboram com um contexto social de vulnerabilidade e violência vivido por pessoas LGBTT no Brasil, mais ainda quando estas são jovens.

Uma pesquisa encomendada pelo Ministério da Educação à Fundação Instituto de Pesquisas Econômicas da USP (FIPE) concluiu que as principais vítimas de bullying e discriminação no ambiente escolar eram, nesta ordem, homossexuais, negros e pobres, e que os atos discriminatórios e preconceituosos impactavam no desempenho médio dos alunos (FIPE, 2009).

Uma pesquisa mais recente, e que demostra que esta realidade nas escolas não mudou, foi realizada pelaAssociação Brasileira de Lésbicas, Gays, Bissexuais, Travestis e Transexuais (ABGLT), junto com a Secretaria da Educação do Paraná, que analisou as experiências de adolescentes e jovens LGBTT em ambientes educacionais brasileiros. Participaram da pesquisa 1016 estudantes de todos os estados brasileiros, exceto Tocantins, com idade entre 13 e 21 anos. Os resultados apontam que $60 \%$ dos participantes se sentia inseguro na escola por se definirem como LGBTT; 73\% disse ter sido agredidos verbalmente e 


\section{REFLECTIONIS \\ REFLECTIONIS}

REVISTA ELETRÔNICA

Volume 13, n, 2, ano, 2017

DA GRADUAÇÃO/PÓS-GRADUAÇÃO EM EDUCAÇÃ O

ISSN. 1807-9342

$36 \%$ afirmou ter sofrido agressões físicas e que a resposta dos profissionais das escolas ineficaz para impedir as agressões, e 39\% dos que sofreram agressões relatouque nenhum membro da família conversou com membros da equipe de profissionais da escola quando o estudante sofreu agressão ou violência.

Estes dados são consonantes com a afirmação de Ventury e Bokany (2011) de quea discriminação às pessoas LGBTTacontece em locais onde elas passam a maior parte do tempo. Explica-se por estes resultados o porquê a escola tem se revelado como um dos espaços onde jovens LGBTT sofrem mais ameaças físicas e psicológicas. Pode-se dizer que se somam a estes dados, reforçando-os, a conjuntura politica nacional atual, o fortalecimento do conservadorismo e de noções como "ideologia de gênero", e o aumento da chamada bancada de parlamentares da "Bíblia", constituída por uma parte de políticos católicos e evangélicose outra parte de outros políticos conservadores, que tem elaborado projetos de leis que ameaçamno Congresso Nacional osdireitos sexuais e reprodutivos já conquistados no país.Nesta conjuntura tem se produzido também discursosque fundamentam as práticas discriminatórias cotidianas às pessoas que não correspondem a heteronormatividade ${ }^{4}$, que culminaram, dentre outros efeitos, na retirada da discussão de gênero e diversidade sexual do Plano Nacional de Educação e dos Planos Municipais de Educação.

Constata-se, como afirma Souza (2014), que alguns setores evangélicos e católicostemdisseminado seus discursos e doutrinas, bem como suas posições e pautas políticopartidárias diariamente nas redes sociais, internet, rádio e TV. As suas lideranças possuem ampla exposição com um alto alcance de produção e transmissão de suas mensagens. Pode-se constatar, também, que este recurso de comunicação foi amplamente utilizado durante a aprovação dos Planos Municipais pelo Brasil em 2015, com intuito de combater ao que denominam "ideologia de gênero" na educação brasileira.

Diante do que foi apresentado, oobjetivo deste artigo é analisar as cenas e discursos da mídia durante a discussão do Plano Municipal de Educação (PME)em Sorocaba-SP,no ano de 2015, quando os vereadores da cidade decidiram retirar todas as menções as palavras "gênero", "diversidade sexual" e "LGBT" do documento com forte pressão de parlamentares e lideranças religiosas, e tecer algumas considerações sobre o quanto estes resultados ressoam os dados sobre discriminaçãode jovens LGBTT na escola.

\footnotetext{
${ }^{4}$ Hetoronormatividade é um conceito que se refere a discursos e práticas por meio das quais a heterossexualidade é instituída como a única forma legítima de expressão sexual.
} 
REVISTAELETRÔNICA

DA GRADUAÇÃO/PÓS-GRADUAÇÃO EM EDUCAÇÃ O

ISSN. 1807-9342

Volume 13, n, 2, ano, 2017

Foi realizada, portanto, a coleta de um total de 52 reportagens, artigos de jornais, imagens na internet durante a discussão do PME na Câmera de Vereadores em 2015 e, em seguida, estes documentos foram sistematizados a fim de evidenciar os seus principais argumentos, ideias e práticas.

Este é um estudo qualitativo, que busca os sentidos e significados dos discursos produzidos no cotidiano, os quais refletem práticas sociais. Parte de uma perspectiva psicossocial na qual se entende que a produção de sentido não é uma atividade cognitivaindividual, mas uma prática social e dialógica que revelam as diferentes formas em que as pessoas produzem, através dos discursos, realidades psicológicas e sociais (SPINK, 2000).

Por fim, o estudo ainda se configura comoinicial e exploratório, demandando um maior aprofundamento e debate sobre a relação entre Estado e Religião no Brasil, e requer uma pesquisa mais aprofundada do cotidiano escolar vivido pelos jovens em Sorocabapara uma análise mais completa.

\section{PME E A "IDEOLOGIA DE GÊNERO": CENAS E DISCURSOS NA MÍDIA EM SOROCABA}

\subsection{O Bispo, o PME e a Ideologia de Gênero.}

Em Junho de 2015 o município de Sorocaba, no Estado de São Paulo, iniciou um intenso debate para a elaboração do Plano Municipal de Educação2015-20125 (PME), conforme estabelecia o Plano Nacional de Educação 2014-2024 (Lei n. 13.005/2014).

O Plano Nacional de Educação (PNE) define as metas, estratégias e diretrizes para a educação brasileira para os próximos dez anos (2014-2024) e se constitui como o documento que fundamenta a elaboração dos planos de educação de cada município. Os planos municipais de Educação devem articular suas metas locais às metas nacionais.

O PNE, sancionado pela Presidenta da República, Dilma Rousseff, em junho de 2014, tem as seguintes metas gerais: a) a garantia do direito à educação básica de qualidade e a promoção do acesso à educação; b) metas específicas sobre valorização da diversidade e redução das desigualdades, para que a equidade possa ser atingida; c) metas em relação à valorização dos profissionais da educação; d) metas para ensino superior (BRASIL, 2014).

No dia anterior à votação do PME na Câmara dos Vereadores em Sorocaba, uma postagem de facebookdo Bispo da cidade circulou nas redes sociais causando tanto indignação, de um lado, como mobilização, por outro. Assim inicia a postagem: 
REVISTA ELETRÔNICA

DA GRADUAÇÃO/PÓS-GRADUAÇÃO EM EDUCAÇÃ O

Volume 13, n, 2, ano, 2017

ISSN. $1807-9342$

Aos Católicos! URGENTE, URGENTÍSSIMO!!!

Insatisfeito com a não inclusão da ideologia de gênero no Plano Nacional de Educação (PNE), (isto é, a ideologia demoníaca de que não existe "menino" ou "menina", "masculino" e "feminino", pois você pode escolher ser quem deseja), o governo federal criou uma estratégia ardilosa para implementá-la em nosso sistema educacional por meio dos planos municipais e estaduais de educação. (Bispo Dom Eduardo Benes de Sales, postagem de Facebook, 25/06/2015, grifos nossos)

Nesta postagem, o Bispo se refere aos estudos e debates sobre gênero, transexualidade, homossexualidade como constituindo uma "ideologia demoníaca" que impõe às crianças e jovens em idade escolar uma sociedade sem gênero, sem "feminino" e sem "masculino". Como estratégia, segundo ele "ardilosa", o governo federal - à época comandado pelo Partido dos Trabalhadores, na pessoa da Presidenta Dilma Rousseff - estaria fazendo um movimento para impor a discussão de gênero nos PME, apesar de ele ter sido retirado do PME.

De acordo com a postagem do Bispo,

[...]o governo tem PRESSIONADO OS MUNICÍPIOS e estados para que insiram "gênero" e "orientação sexual" em todos os PMEs e PEEs do país. Felizmente, muitos municípios em todo o Brasil já aprovaram seus respectivos planos SEM QUALQUER referência a "gênero" ou "orientação sexual". (Bispo Dom Eduardo Benes de Sales, postagem de Facebook, 25/06/2015, grifos nossos)

É sabido que durante o processo de elaboração, debate e aprovação do PNE, segmentos da Igreja Católica e Evangélica promoveram diversas manifestações contra o que chamavam "Ideologia de Gênero" na educação brasileira. Estas manifestações intensas e tensas durante a aprovação do PNE culminaram na retirada das palavras gênero e orientação sexual do plano. O inciso III do artigo $2^{\circ}$ foi modificado para "superação das desigualdades educacionais, com ênfase na promoção da cidadania e na erradicação de todas as formas de discriminação" e a estratégia 3.12 da Meta 3 foi alterada para estratégia 3.13 da meta 3 “implementar políticas de prevenção à evasão motivada por preconceito ou quaisquer formas de discriminação", eliminando do textoas especificações destas discriminações e preconceitos, que seriam por "igualdade racial, regional, de gênero e de orientação sexual" (SOUZA, 2014;ROSADO-NUNES, 2015).

No entanto, apesar da mudança da proposta inicial do PME, os municípios brasileiros teriam autonomia para articular suas próprias metas nos planos municipais de educação, ainda que articuladas com as metas nacionais, seguindo as especificidades regionais e as demandas locais da população. É esta autonomia que o Bispo questiona na postagem com o intuído de justificar a sua posição contrária aos debates de gênero e diversidade sexual no Plano Municipal de Educação de Sorocaba. É importante ressaltar que esses debates foram 
REVISTA LETRÔNICA

DA GRADUAÇÃO/PÓS-GRADUAÇÃO EM EDUCAÇÃ O

ISSN. 1807-9342

Volume 13, n, 2, ano, 2017

demandados pelo Fórum Popular de Educação e outros grupos da cidade que participaram de sua elaboração, que serão descritos adiante neste artigo.

Para complementar, o Bispo também atacouos próprios argumentos destes grupos e seus fundamentos teóricos que visavam o combate à discriminação homo, lesbo, bi e transfóbica nas escolas do município, como segue abaixo:

[...]É bom lembrar que a ideologia de gênero não tem como objetivo combater o preconceito ou ensinar o respeito à diversidade. Essas duas justificativas são desculpas criadas para ocultar o verdadeiro objetivo dos teóricos que criaram essa ideologia: relativizar completamente a definição de família e esvaziar juridicamente a noção de homem e mulher, masculino e feminino. (Bispo Dom EduardoBenes de Sales, postagem de Facebook, 25/06/2015, grifos nossos)

E em seguida faz a convocação aos fiéis, cristãos e católicos:

Em SOROCABA, Quarta-feira próxima, a iniciar-se às 9,00 horas da manhã, a Câmara de Vereadores de Sorocaba, estará reunida para votar o Plano Municipal de Educação. Nessa ocasião a presença dos cristãos é ainda mais necessária do que na audiência do dia oito passado. Assim nos pede nosso ARCEBISPO, DOM EDUARDO: “A presença da Igreja Católica é importante para apoiar os vereadores que deverão votar o Plano impedindo que a ideologia de gênero entre no Plano. (Bispo Dom EduardoBenes de Sales, postagem de Facebook, 25/06/2015, grifos nossos)

No mesmo período, alguns dias antes da postagem, o jornal local de Sorocaba publicou uma reportagem com o seguinte título: "Bispos não aceitam ideologia de gênero na prática pedagógica"5. Segundo a reportagem, os bispos do Regional Sul 1 da Conferência Nacional dos Bispos do Brasil (CNBB), que engloba o estado de São Paulo, divulgaram uma nota em que condenam a ideologia de gênero na educação. Segundo o texto, assinado pelo cardeal Dom Odilo Pedro Scherer, presidente do Conselho Episcopal Regional Sul 1 CNBB, a introdução da ideologia de gênero teria consequências na prática pedagógica das escolas e contradiz "a configuração antropológica de família, transmitida há milênios em todas as culturas". A nota, ainda segundo o jornal, alertou para a possibilidade de inserção da ideologia de gênero nos Planos Municipais de Educação. Em seguida, o jornal afirmou que a nota foi encaminhada ao Executivo e Legislativo Municipal de Sorocaba pelo Arcebispo Metropolitano, Dom Eduardo Benes de Sales, o mesmo da postagem descrita acima.

No Brasil, consonante com a posição do Bispo Dom Eduardo de Sorocaba, outras lideranças religiosas evangélicas e católicas, sobretudo, políticos e uma parte da população, decidiram se posicionar veementemente contra a utilização do termo "gênero" e "orientação sexual" nos Planos Municipais de Educação, combatendo de modo agressivo, incisivo e

${ }^{5}$ http://www.jornalcruzeiro.com.br/materia/616315/bispos-nao-aceitam-ideologia-de--genero-na-praticapedagogica, Acesso em: 10 de Jan. de 2017. 
REVISTAELETRÔNICA

DA GRADUAÇÃO/PÓS-GRADUAÇÃO EM EDUCAÇÃ O

Volume 13, n, 2, ano, 2017

ISSN. $1807-9342$

maciçamente, as iniciativas que tinham como objetivo tratar de temas como orientação sexual, sexualidade e identidade de gênero no espaço escolar. Estes grupos também argumentavam que tais expressões constituíam a chamada "Ideologia de gênero" (SOUZA, 2014)

De acordo com a postagem de 18 de Junho de 2015 do site do Instituto Liberal, muito difundida nas redes sociais no período de votação dos Planos Municipais de Educação no Brasil, cujo título era "Os Perigos da Ideologia de Gênero", o conceito era definido da seguinte forma:

A ideologia de gênero não é nada mais que a negação de que existem sexos ao nascimento, com a afirmação que a sexualidade é uma construção social, onde a pessoa escolheria o que deseja ser. É também implantada na linguagem, com a negação de gênero nas palavras, com a substituição das letras o e a pela letra x; para dar um exemplo, a palavra menino, ou a sua variação no feminino, que seria a palavra menina, transformam-se em meninx, visando a neutralidade.

Em seguida a postagem afirmava que este conceito tem origem nas ideias e teorias de Karl Marx e Friedrich Engels, com o objetivo de destruir a família tradicional e implantar uma sociedade comunista, já que para o comunismo a família é "resultado de uma opressão social produzida pela acumulação da riqueza entre os primeiros povos agricultores", segundo o site. Referiam-se ao livro de Engels "A Origem da Família, da Propriedade Privada e do Estado", em uma análise simplificada, para explicar que o termo gênero não foi usado pelos autores em suas obras porque este não havia sido inventado.

A ideologia de gênero nas escolas, finalizam no artigo, era perigosa porque ignoram

[...] totalmente o direito de escolha dos pais em relação à metodologia de ensino desejada por eles. Segundamente, pela atribuição dos municípios perante o Plano Nacional de Educação, que é a de fornecer a chamada educação básica, que vai do chamado maternal até o quinto ano do ensino fundamental; ou seja, esse tipo de ideologia seria ensinado para crianças de 0 a 10 anos, o que seria uma afronta dos atuais administradores governamentais, "especialistas" em educação, e de suas agendas panfletárias à educação formativa fornecida pelos pais de acordo com os seus preceitos, opiniões, crenças e tradições, numa clara forma de doutrinação ideológica. Terceiro, que o gênero é um conceito ideológico que tenta anular as diferenças e aptidões naturais de cada sexo; e há ainda o quarto aspecto, que consiste em ignorar o indivíduo em prol da formação de militância e blocos coletivos. (grifos nossos)

Nesta postagem, onde não aparece quem foi o/a(s) autor(e)(s), vê-se, concomitantemente, uma simplificação dos conceitos advindos das teorias de gênero, sexualidade, feminista e de economia e política. Não citam referências de teóricos e teóricas clássicos dos estudos de gênero das últimas décadas e apenas, forçosamente, associam a

${ }^{6}$ https://www.institutoliberal.org.br/blog/o-perigo-da-ideologia-de-genero-nas-escolas/, Acesso em: 10 de jan. 2017. 
REVISTAELETRÔNICA

DA GRADUAÇÃO/PÓS-GRADUAÇÃO EM EDUCAÇÃ O

ISSN. 1807-9342

Volume 13, n, 2, ano, 2017

"ideologia de gênero" ao comunismo, quando citam Karl Marx e Friedrich Engels.Com isso, trazem à tona o pânico relacionado ao comunismo utilizado durante o período da ditadura civilmilitar, difundido também pela elite e classe média cristã brasileira, que resultou em perseguições, torturas e mortes de militantes de partidos comunistas e de esquerda pelo governo da ditadura militar, e o reavivam com uma nova roupagem, uma nova perseguição, um novo conceito: ideologia de gênero. A “ideologia de gênero" seria, portanto, nesta definição, uma estratégia ardilosa da militância de esquerda e comunista para destruir a família por meio da educação formal e escolar para, em seguida, implantar o comunismo.

Na mesma linha, de acordo com Souza (2014), a campanha contra ao que denominam "ideologia de gênero" tem como objetivo criar certo "pânico moral" contra o gênero e o feminismo e evocar o tema da sexualidade, tão pautado por setores conservadores da sociedade. Neste sentido, segundo a concepção difundida pelas redes sociais, blogs e internet, tanto por segmentos católicos como evangélicos, romper com padrões heteronormativos é interpretado como uma ameaça à família tradicional, ao cristianismo e, portanto, a toda a sociedade brasileira. Soma-se a este argumento a associação da "ideologia de gênero" com partidos de esquerda de orientação socialista (e comunista), principalmente o PT, e organizações internacionais como Organizações das Nações Unidas, por pautarem a igualdade de gênero em seus programas e acharem que há uma "estratégia ardilosa" de implantar a "ideologia de gênero" no Brasil e deflagrarem a "revolução socialista".

De acordo com a postagem do Pe. Paulo Ricardo, da cidade de Cuiabá, que tem feito uma campanha intensa na internet, em blogs e vídeos no youtubecontra a Ideologia de Gênero, principalmente durante a discussão do PNE e os PME, tendo registrado a totalidade de centenas de milhares de visualizações e compartilhamentos:

\footnotetext{
A ideologia de gênero é uma nova técnica, idealizada, em conjunto com fundações internacionais, pelos partidos de esquerda que pretende, utilizando o sistema escolar, abolir a família como instituição social. Aprovado o Plano Nacional de Educação, no ano que vem poderá ser apresentado outro projeto de lei, que proporá a educação sexual obrigatória nas escolas, sem direito a objeções de consciência por parte dos pais, conforme já faz parte das orientações internacionais da ONU a este respeito. Quando estas duas leis estiverem aprovadas, o sistema educacional brasileiro será transformado em uma máquina armada para a demolição e a destruição da família natural. É a nova revolução socialista de que o PT, orientado por organizações internacionais, é atualmente o principal protagonista no Brasil. Se o Plano for aprovado, nos próximos dez anos nossos filhos serão educados segundo a nova ideologia de gênero (Pe. Paulo Ricardo, site ChristoNihlPraeponere, 10/02/2014, grifos nossos) ${ }^{7}$
}

${ }^{7}$ https://padrepauloricardo.org/blog/urgente-congresso-pode-aprovar-a-ideologia-de-genero-como-meta-daeducacao, Acesso em: 28 de Janeiro de 2017. 
REVISTAELETRÔNICA

DA GRADUAÇÃO/PÓS-GRADUAÇÃO EM EDUCAÇÃ O

ISSN. 1807-9342

Volume 13, n, 2, ano, 2017

Na postagem 122 do Pr. Paulo Ricardo, de 09 de Junho de 2015, cujo título é“A Ideologia de Gênero nos Planos Municipais de Educação", o padre posta um vídeo e um áudio com seguinte legenda: "O perigo está mais próximo do que você imagina. O plano para introduzir a Ideologia de Gênero nas escolas saiu do Congresso Nacional e está nas Câmaras Municipais de todo o país, bem perto da sua casa. Afinal, o que está acontecendo? Como agir diante dessa nova ameaça à família brasileira? Entenda já os riscos e saiba o que fazer". ${ }^{8}$

Em seguida, na mesma postagem, disponibiliza para seus seguidores links de 8 arquivos, que incluem: Documento final da Conferência Nacional de Educação (CONAE) 2014, Carta de Dom Leonardo Steiner contra a Ideologia de Gênero nos PMEs (22 de maio de 2015), Requerimento de Informação n. 565/2015, do Deputado Izalci (PSDB-DF), Discurso do Deputado Victorio Galli (PSC-MT) sobre a Ideologia de Gênero (15 de abril de 2015), Cartilha "Você já ouviu falar sobre a 'Ideologia de Gênero'?" e um arquivo com uma lista de referências importantes sobre a Ideologia de Gênero. Todos os arquivos tinham como objetivo servir de base a manifestações contra a Ideologia de Gênero nos PME nas Câmaras de Vereadores. Os comentários (total de 54) da postagem, em sua maioria, são de gratidão, concordância e de solicitação de ajuda para combater a ideologia de gênero nas suas próprias cidades.

Para além das distorções e confusões apresentadas sobre as teorias de gênero, feministas e da sexualidade, ficam evidentes nestas postagens uma mistura de religião e política e uma interferência clara das igrejas no poder público, legislativo e executivo, quando na formulação das políticas de educação, o que coloca em questão a laicidade do Estado brasileiro.

Retomando um percurso histórico, necessário para a compreensão das relações entre Estado e religião, o projeto de laicização no Brasil teve seu início no século XIX, quando, segundo Giumbelli (2008), assume-se o princípio da separação entre Estado e igrejas, em específico a Igreja Católica. Diante deste rompimento, o casamento se torna civil, os registros civis deixam de ser eclesiástico, o ensino público é declarado laico e princípios como o da liberdade religiosa e igualdade dos grupos confessionais são incorporados na primeira Constituição Republicana de 1891.

${ }^{8}$ https://padrepauloricardo.org/episodios/a-ideologia-de-genero-nos-planos-municipais-de-educacao, Acesso em: 28 de Janeiro de 2017. 
REVISTAELETRÔNICA

DA GRADUAÇÃO/PÓS-GRADUAÇÃO EM EDUCAÇÃ O

ISSN. 1807-9342

\section{Volume 13, n, 2, ano, 2017}

No entanto, a Igreja Católica permaneceu atuante nas definições da nova relação entre a religião e o Estado e, como esperado, se posicionou contra a separação entre Estado e religião. Como não foi possível um regime contrário à laicização, as suas lideranças defendiam o reconhecimento da superioridade do catolicismo na formação da nacionalidade brasileira. Esta reivindicação da Igreja Católica teve resultados anos depois.

Tais empenhos foram em parte recompensados no texto da Constituição de 1934, na qual, por exemplo, o ensino religioso é permitido e o casamento religioso volta a ter validade civil; além disso, o princípio da separação é temperado pela possibilidade de "colaboração" entre Estado e religiões. A noção de "colaboração" conferiu assim um fundamento constitucional para aproximações entre Estado e religiões, o que, naquele momento histórico, traduziu as vitórias conquistadas pela Igreja CatólicaGIUMBELLI, 2008, p. 82).

Assim, para Giumbelli (2008), os movimentos de secularização e os desdobramentos da laicidade, sobretudo na experiência brasileira, se caracterizam muito maiscomo de complementação entre a religião e o Estado. Como podemos observar no momento atual, esta complementação permanece vívida, principalmente, por exemplo, quando analisamos as últimas campanhas eleitorais presidenciais no Brasil, quando temáticas como aborto e casamento homoafetivo eram colocadas em pauta com viés religioso; ou o aumento expressivo da chamada "bancada religiosa" nos Congresso Nacional e nas Câmaras de Vereadores e, no caso aqui estudado, na interferência forte e contundente na aprovação do PNE e nos PME.

No entanto, é importante partir do entendimento de que a presença da religião no espaço público não é construída por oposição a secularização, mas de que

[...]foi no interior da ordem jurídica encimada por um Estado comprometido com os princípios da laicidade que certas formas de presença da religião ocorreram. Em segundo lugar, tampouco é o caso de deixar de problematizar essa situação, o que acaba sendo o efeito de muitas análises que se contentam em destacar a ininterrupta vitalidade do campo religioso brasileiro (GIUMBELLI, 2008, p.81).

Por fim, seguindo estes argumentos de Giumbelli (2008), entende-se que, embora o Estado seja laico (e por causa desta laicidade), é necessário ressaltar que a presença do religioso na sociedade brasileira se relaciona com os dispositivos estatais, e esta vitalidade do campo religioso se pode constatar nos debates dos planos de educação, tanto em nível nacional como municipais.

Souza (2014), por sua vez, esclarece que uma agenda moralista tem sido projetada por segmentos conservadores da sociedade nos últimos anos, apoiados (e estimulados) por grupos religiosos do Brasil e também do Exterior. $\mathrm{O}$ alvo tem sido as pautas dos direitos sexuais e reprodutivos, o movimento feminista e LGBTT. Ainda segundo a autora, o "moralismo 


\section{REFITECTIONIS \\ REFLETIONIS}

Volume 13, n, 2, ano, 2017

REVISTA ELETRÔNICA

DA GRADUAÇÃ O/PÓS - GRADUAÇÃ O EM E D U C A Ç Ã O

ISSN. 1807-9342

sexual" tem constituído "complexas composições na arena político-religiosa do país no que tange o debate de gênero e laicidade" (p.199).

Pode-se entender que os movimentos de defesa do estado laico e secularização, que fundamentam a separação entre religião e Estado, tem reduzido ainda mais suas forças quando se tratam de temas que envolvem gênero e sexualidade. Conforma argumentam Ribeiro, Pataro e Mezzono (2016), as discussões em relação ao tema dos direitos sexuais e reprodutivos tem mostrado que a religião tem ocupando lugar de destaque na política, e, consequentemente, tem influenciado na definição de políticas públicas.

Esta realidade não se mostrou diferente quando da discussão e aprovação do PME em Sorocaba, como pode ser observado pelas postagens descritas, e pode ser entendida, conforme Souza (2014, p.189-190), como um modo de "violência de gênero que se traduz na ação político-religiosa desses seguimentos, seja obstaculizando a luta pela ampliação dos direitos das mulheres e da população LGBTT, seja lutando contra direitos já conquistados por esses grupos".

\subsection{Querelas da Ideologia de Gênero na aprovação PME (2015-2015) em Sorocaba (SP)}

Em Sorocaba, quando da aprovação do PME, a bancada da Câmara de Vereadores (Legislatura 2013-2016), era constituída por 24 parlamentares:23 homens e 01 mulher. Quanto aos partidos que estão filiados, segundo o site, 05 não estão em partido ou não o divulgaram, 03 do PRP, 03 do PSDB, 03 do PT, 02 do PRB. Os partidos DEM, PPS, PROS, PSB, PV, PR, PMDB, SDD tinham um vereador cada. Portanto, a Câmara de Vereadores, no período da aprovação do PME, possuía um perfil majoritário de partidos considerados de direita ou centrodireita, que tem levado tradicionalmente pautas conservadoras para os parlamentos brasileiros.

Dos 24 vereadores, seguindo a descrição e biografia do site oficial da Câmara de Vereadores de Sorocaba ${ }^{9}$, havia 3 Pastores, 01 pastora e 01 Missionário que destacaram sua atuação como lideranças religiosas em seus mandatos. Todos de igrejas de denominações evangélicas.

Ao analisar a composição da banda evangélica na Câmara de Vereadores de Sorocaba, fica evidente que a inserção dos evangélicos na sociedade brasileira nas últimas décadas, como ressalta Gumbelli (2008), não se dá apenas em seu aspecto numérico, mas principalmente por sua ação no campo da política. Assim, muitas igrejas de denominação

${ }^{9}$ http://www.camarasorocaba.sp.gov.br/sitecamara/index.jsp, Acesso em: 20 de Janeiro de 2017. 
REVISTAELETRÔNICA

DA GRADUAÇÃO/PÓS-GRADUAÇÃO EM EDUCAÇÃ O

ISSN. 1807-9342

Volume 13, n, 2, ano, 2017

evangélica tem apoiado candidaturas legislativas com identidade religiosa (muitos se apresentam e querem ser chamados de pastor, missionário, irmão, etc.) e se mobilizam em defesa de seus interesses para além de suas denominações específicas, criando frentes parlamentares e participando na execução de políticas públicas e de parcerias com órgãos governamentais. Portanto, a complementariedade entre religião e Estado se legitima, o que não ocorre de modo diferente no município de Sorocaba.

Embora não divulgado oficialmente, também é de notório conhecimento que grande parte dos demais vereadores manifesta suas crenças religiosas católicas ou evangélicas em espaços públicos ou redes sociais. Um exemplo é, à época, do vereador José Crespo (DEM), hoje prefeito da cidade de Sorocaba-SP, quando no período dos debates do PME, postou em sua rede social:

[...]de fato, eu não estava bem estou lá para "agradar" a todos, e sim para tentar fazer a coisa certa, com mandato popular. Os GLBTTTT (sic), como se auto-denominam, merecem ser respeitados e gozar de todos os direitos civis, mas são pessoas anormais (divergem dos padrões cristãos de normalidade) e, num país cristãocomo o Brasil, não devem ditar regras de comportamento social (José Crespo, postagem de facebook em 24 de Junho de 2015, grifos nossos)

Com base em preceitos que se justifica como cristãos, o ex-vereador chamou as pessoas LGBTT de "anormais" e, em seguida, em outra postagem, atacou os ateus em discussão nos comentários de facebook:

Sim, amigo Erisson, os conceitos de "laico" e "ateu" são diferentes. O Brasil, por exemplo, é um Estado laico ma não é um Estado ateu (prova disso é que em todas as cédulas de papel-meda, está escrito "Deus seja Louvado"). Somente alguém muito buro ou ignorante não acredita em Deus (devemos ter caridade e ajudar uma pessoa nessa situação)(José Crespo, postagem de facebook em 24 de Junho de 2015, grifos nossos)

Diante das declarações, as postagens do ex-vereador, foram exaustivamente divulgadas pelos movimentos LGBTT e ateus, adquirindo repercussão nacional. Na reportagem publicada em 25 de Junho de 2015 no site do Jornal Cruzeiro do Sul, um dos mais populares de Sorocaba, cujo título foi "Crespo chama LGBTs de 'anormais' e ateus de 'burros" ", , a coluna apresentou a justificativa das declarações feitas:

À coluna, Crespo confirmou suas declarações e procurou justificá-las: "Anormal é simplesmente aquilo que destoa do "normal". E normal é o "comum", o perfil mediano de algo, nesse caso de uma Sociedade. E não significa julgamento de valor, ou seja, o "anormal" não necessariamente é "mau", nem "bom", nem "certo" nem "errado"." E completou: "As atitudes dos" "ideólogos de gênero", na Câmara ontem, pretenderam influenciar o comportamento das crianças dentro das escolas públicas, eu expliquei que essa minoria (bem como qualquer outra minoria) tem todos os direitos civis da Constituição Federal e deve ser respeitada, mas não

\footnotetext{
${ }^{10} \mathrm{http} / / /$ www.jornalcruzeiro.com.br/materia/619636/crespo-chama-lgbts-de-anormais-e-ateus-de-burros,
} Acesso em: 20 de Janeiro de 2017. 
REVISTAELETRÔNICA

DA GRADUAÇÃO/PÓS-GRADUAÇÃO EM EDUCAÇÃ O

ISSN. 1807-9342

Volume 13, n, 2, ano, 2017

deve ditar as regras de comportamento da maioria, que no Brasil, é cristã. Embora o Estado brasileiro seja laico, o povo é cristão e esse povo (maioria) não aceita essa "ideologia de gênero".

A justificativa das declarações se fundamenta novamente no conceito de "ideologia de gênero" e na cristianidade da cultura brasileira e do Estado. Os "ideólogos de gênero" são entendidos como aqueles que não respeitam e não devem "ditar regras de comportamentos" da maioria, seguindo os argumentos contra a ideologia de gênero utilizado pelas lideranças religiosas católicas e evangélicas e desconsiderando todos os estudos e pesquisa na área de gênero e sexualidade.

Este caso exemplifica um dos modos como se estabelece a complementariedade entre o Estado Brasileiro e Religião, citado por Gumbelli (2008), já que estamos tratando aqui de declarações de um parlamentar, que à época legislava no município e que assumiu neste ano um cargo executivo, sobre uma política pública, visto que estas declarações estavam sendo feitas e divulgadas quando a discussões do PME: a força dos argumentos de religiosos possui primazia aos da ciência, das pesquisas e das experiências vividas quando da definição de políticas públicas, sendo estes últimos ignorados ou rechaçados.

O Plano Municipal de Educação foi elaborado, tal como é previsto por lei, a partir da mobilização da sociedade civil e da comunidade escolar. Estavam presentes "um coletivo de educadores, pais e estudantes que buscaram garantir, neste percurso, novas formas de participação social" (FERREIRA et al, 2016, p. 82).

No entanto, embora com todo aparato legal que ampara, tais como a Constituição Federal, a LDB, o PNE,a participação da comunidade nas formulações das políticas para a escola pública, o poder executivo e legislativo de Sorocaba, durante o processo de elaboração do PME, parece ter criado algumas dificuldades para esta participação logo no início da elaboração do PME. Porém, houve um engajamento e participação de educadores movimentos populares e a comunidade na denúncia e reivindicação de uma proposta de PME substancialmente coletiva, dialógica e democrática. O resultado foi uma um PME que refletia as posições de cerca de 520 delegados que estavam representando os mais diversos segmentos da sociedade Sorocaba. Neste PME se incluíam pautas de gênero, diversidade sexual e LGBT. (FERREIRA et al, 2016)

No entanto, sem qualquer discussão, o documento construído chegou aos vereadores e à plenária no dia da votação na Câmara dos Vereadores em 23 de Junho de 2015 modificado e sem as metas relacionadas a gênero, diversidade sexual e LGBTT incluídas. Esta 
REVISTAELETRÔNICA

DA GRADUAÇÃO/PÓS-GRADUAÇÃO EM EDUCAÇÃ O

\section{Volume 13, n, 2, ano, 2017}

ISSN. 1807-9342

retirada dos debates de gênero e da diversidade sexual gerou uma onda de protesto e articulação dos coletivos LGBTT da cidade para manifestação na Câmara, junto com o chamamento de lideranças religiosas, como o do Bispo Dom Eduardo, para a presença maciça de religiosos para a defesa da família tradicional e contra a ideologia de gênero, além de solicitação para que se incluísse no PME o ensino religioso nas escolas sorocabanas.

Em reportagem da página da coluna educação "UOL Educação" ${ }^{11}$, de 24 de Junho de 2015, o acontecimento é relatado:

Religiosos e militantes dos direitos GLBTT (Gays, Lésbicas, Bissexuais, Transexuais e Transgêneros) participaram de um protesto, na manhã de hoje (24), na Câmara de Sorocaba, pedindo mudanças no PME (Plano Municipal de Educação) da cidade. Grupos religiosos pediam a inclusão do ensino religioso, enquanto os defensores da causa GLBTT queriam a inclusão de identidade de gênero nas práticas pedagógicas municipais. Mesmo após a invasão do plenário e de manifestações com faixas e cartazes, o projeto, que não contempla nenhuma das reivindicações, foi aprovado.

Uma mudança de última hora no texto foi a causa dos protestos. Cerca de 250 manifestantes estiveram na Câmara, segundo a Guarda Civil Municipal, que precisou mandar um efetivo de 20 homens para garantir a segurança do evento.

A proposta original da prefeitura, enviada no começo de junho, foi construída após debate com a sociedade sorocabana em processo que começou em agosto de 2014. Nela, estavam inclusas algumas ações sobre a identidade de gênero, mas um novo projeto, substitutivo, retirou 33 estratégias da propositura original e foi enviado à Câmara ontem.

Parte dos vereadores não aprovou as mudanças e Izídio de Brito (PT) protocolou um projeto de lei que substitui a proposta do Executivo e inclui a identidade de gênero e o ensino religioso na prática pedagógica. O projeto substituto petista não chegou a ser discutido, sendo a proposta do prefeito Antonio Carlos Pannunzio (PSDB) aprovada pelos parlamentares.

Muitos consideraram a maior manifestação ocorrida na Câmara de Vereadores de Sorocaba em toda a sua história. Na manifestação tinha um número visivelmente superior de religiosos (católicos e evangélicos), com cruzes na mão, cartazes contra a "ideologia de gênero" e em defesa da família tradicional, e até havia uma pessoa com um livro de Olavo de Carvalho em mãos e levantado sobre a cabeça ${ }^{12}$. Gritos, bíblias e cruzes eram direcionados aos militantes LGBTT da cidade, que, em sua maioria, eram jovens do ensino médio e universitários, que, embora assustados e indignados, resistiram até o último momento. O Fórum Popular de Educação e outras entidades e grupos que participaram da elaboração do PME também estavam presentes. O PME modificado pela prefeitura de Sorocaba-SP, sem a inclusão de gênero e

\footnotetext{
${ }^{11}$ https://educacao.uol.com.br/noticias/2015/06/24/mudancas-no-pme-desagradam-religiosos-e-militantes-dacausa-gay-em-sorocaba.htm, Acessado em 20 de Janeiro de 2017.

${ }^{12}$ Olavo de Carvalho é um escritor brasileiro que tem um blog e vídeos do youtube que faz críticas agressivas aos movimentos LGBT e à ideologia de gênero
} 
REVISTA LLETRÔNICA

DA GRADUAÇÃO/PÓS-GRADUAÇÃO EM EDUCAÇÃ O

ISSN. 1807-9342

Volume 13, n, 2, ano, 2017

diversidade sexual, foi aprovado, com apenas 03 votos contrários, todos da bancada do PT. No final os religiosos, entre palmas e festejo, repetidamente, gritaram: “A família venceu!”, frase esta repetida nos discursos finais de alguns vereadores, que no final da sessão rezaram o "PaiNosso".

Novamente temos a laicidade do Estado em questão, uma relação íntima e forte das lideranças religiosas e o poder público legislativo e executivo. Vale ressaltar, como exemplo, que na audiência pública em 08 de Junho de 2015, data anterior da data de votação do PME, estavam na mesa para pronunciamentos oficiais o vereador Luis Santos (Pros), pastor evangélico e presidente da Comissão de Educação e Pessoa Idosa, os vereadores Anselmo Neto (PP) e Pastor Apolo (PSB), o vereador Carlos Leite (PT), o arcebispo Dom Eduardo Benes de Sales Rodrigues, o secretário interino de Educação, Flaviano Agostinho de Lima; a presidente do Conselho Municipal de Educação, Laurita Hotlz Batistuzz; e o presidente do Conselho de Pastores, pastor Eduardo Bortolossi.

Nesta audiência pública, representantes de várias entidades e coletivos fizeram uso da palavra, apresentando sugestões e críticas, e defenderam veementemente as discussões de gênero nas escolas de Sorocaba e defenderam o "estado laico". Todas as críticas e defesas dos representantes foram ignoradas ou rechaçadas por parte da mesa. A palavra final, antes do encerramento feito pelo Secretário da Educação, foi dada ao Arcebisbo Dom Eduardo Benes.

Osite religioso Nave.org ${ }^{13}$ na matéria, publicada em 09 de Junho de 2015, "Plano Municipal de Educação é discutido em audiência pública na Câmara”, assim relata:

Ao final dos trabalhos, o arcebispo Dom Eduardo Benes, em nome dos demais representantes religiosos, defendeu o conceito de família previsto na Constituição, como união entre homem e mulher, mas garantindo o respeito à diversidade. "A defesa da definição tradicional de família que está consolidada na Constituição Federal em nada impede a obrigação que temos de respeitar a diversidade de opções na área da sexualidade" (grifos nossos)

Conforme pode ser observado nas postagens e relatos acima, a querela da ideologia de gênero, que justificou a retirada de gênero e diversidade sexual das metas no PME de Sorocaba, reforça a família heteronormativa e compulsória, e cria barreiras paraque jovens tenham a possibilidade de debate e discussão da temática na escola, reforçando preconceitos e discriminações, bem como violências. Não que tenha se tornado proibido em Sorocaba, como em outras cidades brasileiras, até este data, trabalhar com questões de gênero e diversidade sexual nas escolas, mas todo este debate e embate em torno dos temas gênero e diversidade

\footnotetext{
${ }^{13}$ https://nave.wordpress.com/2015/06/09/plano-municipal-de-educacao-e-discutido-em-audiencia-publica-nacamara/, Acessado em 20 de Janeiro de 2017.
} 
REVISTAELETRÔNICA

DA GRADUAÇÃO/PÓS-GRADUAÇÃO EM EDUCAÇÃ O

ISSN. 1807-9342

Volume 13, n, 2, ano, 2017

sexual no PME tem tido efeitos em curto e médio prazo que são preocupantes. Muitas escolas públicas de Sorocaba tem evitado que estudos, palestras e aulas que abordem os temas "gênero" e "sexualidade" aconteçam, ou, se são tratados, apenas acontecem com acompanhamento da coordenação ou direção da escola com a justificativa de os/as alunos/as são de família religiosas e podem não aceitar.

Outro efeito foi, logo após aprovação do PME, foi a aprovação da Lei Ordinária 11185, por 15 votos a favor e 03 contrários, que pró́be a utilização de banheiros, vestiários e demais espaços segregados, de acordo com a identidade de gênero, nas instituições de ensino fundamental, público ou privado, instaladas no âmbito do Município de Sorocaba (SP).

A Lei é de autoria do vereador Irineu Toleto (PRB), que também é Pastor da Universal do Reino de Deus, que em entrevista para o Portal Estado OnLine ${ }^{14}$, disse que o objetivo da Lei era o de proteger "o psicológico das crianças, já que o ensino fundamental abrange alunos com idade 7 a 14 anos".

O projeto foi repudiado pelos coletivos e movimentos LGBTT, vetado inicialmente pelo prefeito da cidade e questionado pela Defensoria Pública, mas, enfim, entrou em vigor em 28/09/2015.

Outras leis municipais, respaldadas por um PME em Sorocaba sem as questões de gênero e diversidade sexual em seu texto, podem seguir esta linha de ataque aos direitos sexuais e reprodutivos de jovens nas escolas, contribuindo, deste modo, para o agravamento da violência contra LGBTT.

Portanto, parece necessário e urgente a criação de ações estratégicas de combate à homo, lesbo, bi e transfobia, tais como: espaços de trocas, redes de diálogos, conhecimento, lazer, cultura, esportes, de modo a fazer com que a cidade de Sorocaba seja um lugar privilegiado de sociabilidade e de respeito às diferenças e que contemple o debate sobre os efeitos discriminatórios da heteronormatividade e, assim, seja possível fortalecer um contradiscurso que resista às tentativas do legislativo e executivo de formularem novas políticas que ameacem os direitos sexuais e reprodutivos.

\section{CONSIDERAÇÕES FINAIS}

Muitos cartazes levados nas Câmaras de Vereadores pelo Brasil e durante a manifestação contra e a favor da PME em Sorocaba, observados nas sessões da câmara e

\footnotetext{
${ }^{14} \mathrm{http} / / /$ www.oestadoce.com.br/nacional/lei-proibe-transgeneros-de-usar-banheiro-errado-em-escolas-desorocaba
} 


\section{REFLECTIONIS \\ REFLECTIONIS}

REVISTA ELETRÔNICA

Volume 13, n, 2, ano, 2017

DA GRADUAÇÃO/PÓS-GRADUAÇÃO EM EDUCAÇ ÃO

ISSN. 1807-9342

divulgados na internet, tinham os seguintes dizeres escritos: "Menino já nasce menino, menina já nasce menina. Diga não à ideologia de Gênero", "família é homem e mulher e filhos", "Diga não à Ideologia de Gênero", "Gênero: vai pra Cuba, aqui não!”, “O Diabo não consegue destruir Deus, mas tenta destruir a verdadeira obra de Deus: a Família", "O Estado é Laico, o Povo Não", "Retirem do PME os termos: Gênero, Orientação Sexual, Diversidade, Diversidade Sexual, Questões de Gênero", dentre outros

O que temos é um discurso de defesa da chamada "Família Tradicional", que nada mais é que um discurso de legitimação da heteronormatividade na sociedade. Além disso, associam quaisquer críticas à esta normatividade em teorias e práticas como um conjunto chamado de "ideologia de gênero", algo que é demoníaco e socialista/comunista. Neste discurso excluem e invisibilizam a diversidade de identidades de gênero e de orientação sexual, tornando abjetas, estranhas e passíveis de violência, como consequência, as pessoas que resistem à estas normas. Fundamenta, portanto, aquilo que Junqueira (2012) chama de "pedagogia do insulto" no cotidiano escolar, que são atos discriminatórios e que tem transformado a escola em uma dos lugares mais perigosos para jovens LGBTT. A pedagogia do insulto é:

[...] uma série de tratamentos preconceituosos, medidas discriminatórias, ofensas e
constrangimentos, ameaças e agressões físicas ou verbais têm sido uma constante na
vida escolar e profissional de jovens e adultos que, de maneira dinâmica e variada,
podem se identificar ou ser identificados/as como lésbicas, gays, bissexuais, travestis,
transexuais (LGBT) ou outras categorizações semelhantes, análogas ou equivalentes.
(JUNQUEIRA, 2012, p. 212-213)

A escola, diante deste quadro, é chamada para ações e práticas que possam combater a violência e discriminação homo, lesbo, bi e transfóbica, ainda mais quando os discursos da "ideologia de gênero" advindo de segmentos religiosos em complementariedade com o Estado estão constantemente sendo proferidos e interferindo em políticas educacionais, sociais e públicas.

Natividade e Oliveira (2009) em estudo sobre as relações contemporâneas entre religiões cristãs, diversidade sexual e formas de homofobia, identificaram uma reinvenção de imagens do homossexual como de ameaça à saúde coletiva e de doença como castigo divino, algo que promove risco e perigo, que destrói os "valores" cristãos e o modelo de família tradicional, por eles definido. Estes discursos, tão semelhantes aos postos nas discussões sobre ideologia de gênero difundida pelas lideranças religiosas, estão presentes na escola e na relação das/os profissionais da educação e as/os alunos. 
REVISTA ELETRÔNICA

DA GRADUAÇÃO/PÓS-GRADUAÇÃO EM EDUCAÇÃ O

ISSN. 1807-9342

\section{Volume 13, n, 2, ano, 2017}

Sabe-se que concepções religiosas muitas vezes justificam as práticas no cotidiano escolar e na definição do currículo e práticas de ensino e, assim, tem legitimado a discriminação vivenciada por jovens LGBTT, já identificadas e analisadas em diversos estudos (ALTMANN, 2013; DINIS, 2008; JUQUEIRA, 2012). Estas práticas tem se reproduzido nas vivências de jovens na região de Sorocaba, como revela estudo realizado durante a Parada do Orgulho LGBT de Sorocaba, quando $71 \%$ das/os respondentes, em sua grande maioria jovens, relataram ter sofrido alguma agressão e discriminação por ser homossexual, sendo a escola/faculdade $(32,7 \%)$ e ambiente religioso $(30,3 \%)$ um dos locais onde mais sofrem discriminação, e, além disso,

[...]nota-se que entre as/os criadas/os em religiões evangélicas, $75 \%$ refere ter sofrido algum tipo de violência, contra $65 \%$ das/os criadas/os em outras religiões ou em nenhuma religião. (GARCIA, MENDONÇA e LEITE,2016,p.56)

Corroborando com os argumentos de Giumbelle (2008) fica evidente no caso das discussões divulgadas na internet em torno do PNE e PME no Brasil e no debates da Ideologia de Gênero da Educação, e ainda no caso específico de Sorocaba (SP), que as relações entre religião e Estado brasileiro sempre ocorreram e que em suas fronteiras nunca foi construído um muro; muito pelo contrário, estes sempre estão em diálogo, o que não quer dizer que devamos nos abster de uma análise crítica desta relação e diálogo e da defesa da completa laicidade do Estado brasileiro. Assim,

Vê-se que não se pode problematizar o espaço público sem atentar paraas condições dos atores que se localizam na sociedade; a noção, no entanto, coloca permanentemente em jogo a constituição e o papel do Estado. Estamos, assim, ainda às voltas com o argumento da secularização e sua expectativa para a relação entre religião e espaço público (GIUMBELLI, 2008, p.97)

Portanto, a retórica da ideologia de gênero e os acontecimentos que se seguiram nas aprovações do Plano Nacional e Municipais de Educação no país, não é um assunto que diz respeito apenas à religião, ou a uma briga entre religião e os estudiosos de gênero e dos movimentos LGBTT, mas a algo mais profundo, que diz respeito a produção de práticas discursivas no cotidiano, tendo as redes socais e internet como um dos meios mais utilizados. Estas práticas discursivas dão sentido e se traduzem em práticas sociais, de poder, de regulação e controle de corpos, e, neste caso, de corpos de jovens das escolas brasileiras; e, mais ainda, revelam uma relação de complementariedade e interdependência entre religiões cristãs e poderes legislativos e executivos, o que coloca perigosamente em questão a laicidade do Estado brasileiro.

\section{REFERÊNCIAS BIBLIOGRÁFICAS}


REVISTAELETRÔNICA

DA GRADUAÇÃO/PÓS-GRADUAÇÃO EM EDUCAÇÃ O

ISSN. 1807-9342

Volume 13, n, 2, ano, 2017

ALTMANN, Helena. Diversidade sexual e educação: desafios para a formação docente.

Sexualidad, Salud y Sociedad-Revista Latinoamericana, n. 13, p. 69-82, 2013.

ABGLT- ASSOCIAÇÃO BRASILEIRA DE LÉSBICAS, GAYS, BISSEXUAIS, TRAVESTIS E TRANSEXUAIS. SECRETARIA DE EDUCAÇÃO. Pesquisa Nacional sobre o Ambiente Educacional no Brasil 2015: as experiências de adolescentes e jovens lésbicas, gays, bissexuais, travestis e transexuais em nossos ambientes educacionais. Curitiba: ABGLT, 2016.

BRASIL. Ministério da Educação / Secretaria de Articulação com os Sistemas de Ensino (MEC/ SASE). Planejando a Próxima Década Conhecendo as 20 Metas do Plano Nacional de Educação. 2014.

Disponível em:<http://pne.mec.gov.br/images/pdf/pneconhecendo20metas.pdf >. Acesso em: 22 set. 2016. DINIS, Nilson. F. Educação, relações de gênero e diversidade sexual. Educação \& Sociedade, Campinas, v. 29, n. 103, p. 477-

FERREIRA, Dulcinéia et al. Como uma onda no mar: o jogo de forças entre regulação e emancipação no processo de construção do Plano Municipal de Educação em Sorocaba-São Paulo. Crítica Educativa, v. 2, n. 1, p. 79-95, 2016.492, 2008.

FIPE. Pesquisa sobre Preconceito e Discriminação no Ambiente Escolar. São Paulo/ Brasília: MEC/INEP. 2009, 240 p.

GARCIA, Marcos R. V;; MENDONÇA, Viviane M.; LEITE, Kelen C. Discriminação e violência homofóbicasegundo os participantes da $6^{a}$ Parada do Orgulho LGBT de SorocabaSP: subsídios para (re) pensar as práticas educativas. Cadernos de Pesquisa, v. 22, n. 3, p. 42$58,2015$.

GIUMBELLI, Emerson. A presença do religioso no espaço público: modalidades no Brasil. Religião e Sociedade, Rio de Janeiro, v. 28, n. 02, p. 80-101, 2008.

GRUPO GAY DA BAHIA. Relatório 2016 - Assassinatos LGBT no Brasil. Grupo Gay da Bahia: $\quad$ Salvador, $2017 . \quad$ Disponível em $<$ https://homofobiamata.wordpress.com/estatisticas/relatorios/>, Acesso em 20 de Jan. de 2017.

JUNQUEIRA, Rogério D. Pedagogia do armário e currículo em ação: heteronormatividade, heterossexismo e homofobia no cotidiano escolar. MILSKOLCI, Richard (Org.). Discursos fora da Ordem: deslocamentos, reinvenções e direitos. São Paulo: Annablume, 2012. 


\section{ITTMERARIUS REFLECTIONIS}

REVISTAELETRÔNICA

DA GRADUAÇÃO/PÓS-GRADUAÇÃO EM EDUCAÇÃ O

Volume 13, n, 2, ano, 2017

ISSN. 1807-9342

NATIVIDADE, Marcelo; OLIVEIRA, Leandro. Sexualidades ameaçadoras: religião e homofobia (s) em discursos evangélicos conservadores. Sexualidad, Salud y SociedadRevista Latinoamericana, n. 2, p. 121-161, 2009

PIERUCCI, Antônio Flávio. A propósito do auto-engano em sociologia da religião. Novos Estudos CEBRAP, São Paulo, n. 49, p. 99-117, nov. 1997.

RIBEIRO, Amanda; DE OLIVEIRA PÁTARO, Cristina Satiê; MEZZOMO, Frank Antonio. Religião e "Ideologia de Gênero" no Plano Nacional de Educação (PNE). Revista RelegensThréskeia, v. 5, n. 2, p. 56-70, 2016.

ROSADO-NUNES, Maria José F. A “ideologia de gênero” na discussão do PNE: a intervenção da hierarquia católica. Horizonte, Belo Horizonte, v. 13, n. 39, p. 1237-1260, jul./set. 2015 SOUZA, Sandra D. "Não à ideologia de gênero!” A produção religiosa da violência de gênero na política brasileira. Estudos de Religião, v. 28, n. 2, p. 188-204, 2014.

SPINK, Mary J. Práticas discursivas e produção de sentidos no cotidiano: aproximações teóricas e metodológicas. Cortez, 2000.

VENTURI, Gustavo; BOKANY, Vilma. (Org.). Diversidade sexual e homofobia no Brasil. São Paulo: Ed. Fundação Perseu Abramo, 2011. 